\title{
Current therapeutic agents and anesthetic considerations for diabetes mellitus
}

\author{
Hyoseok Kang \\ Department of Anesthesiology and Pain Medicine, Eulji General Hospital, Eulji University, Seoul, Korea
}

As the incidence of diabetes mellitus (DM) continues to increase worldwide, more diabetic patients will be presented for surgery and anesthesia. This increase of DM is a consequence of the rise in new patients of type $2 \mathrm{DM}$, and is likely attributable to rapid economic development, improved living standards, aging population, obesity, and lack of exercise. The primary goal of management in DM is to delay, or prevent the macro- and microvascular complications by achieving good glycemic control. More understanding of the pathophysiology of DM has contributed to the advance of new pharmacological approaches. In addition to the conventional therapy for DM, glucagon-like peptide-1 (GLP-1) mimetics, dipeptidyl peptidase-4 (DPP-4) inhibitors, thiazolidinediones (TZDs), and insulin analogues are currently available effective hypoglycemic agents for the management of the patients with DM in the perioperative period and also consider the adverse effects of newly introduced agents that need more clinical observations. (Korean J Anesthesiol 2012; 63: 195-202)

Key Words: Anesthesia, Diabetes mellitus, Glucose, Hypoglycemia, Treatment.

\section{Introduction}

The International Diabetes Federation (IDF) reported in 2008, that 246 million adults worldwide had diabetes mellitus and prevalence was expected to reach 380 million by 2025 [1]. Korea National Health and Nutrition Examination Surveys (KNHANES) reported $9 \%$ of the adult population as the prevalence of DM in Korea in 2008 and Task Force Team for Basic Statistical Study of Korean Diabetes mellitus reported in 2007, that the number of patients with type 2 diabetes was expected to increase dramatically from about 3.5 million in $2010(7.08 \%$ of the total population) to about 5.5 million (10.85\%) by 2030 [2]. This increase of DM is a consequence of the rise in new patients of type $2 \mathrm{DM}$, and is likely attributable to rapid economic development, improved living standards, aging population, obesity, lack of exercise and Westernized lifestyle [3]. Type 2 diabetes is remained as the leading cause of cardiovascular disorders, blindness, end-stage renal failure, amputations, and hospitalizations. It is also associated with increased risk of cancer, serious psychiatric illness, cognitive decline, chronic

Received: July 10, 2012. Revised: July 20, 2012. Accepted: July 20, 2012.

Corresponding author: Hyoseok Kang, M.D., Ph.D., Department of Anesthesiology and Pain Medicine, Eulji General Hospital, Eulji University, 280-1, Hagae-dong, Nowon-gu, Seoul 139-711, Korea. Tel: 82-2-970-8350, Fax: 82-2-970-3850, E-mail: hskang0108@eulji.ac.kr (C) This is an open-access article distributed under the terms of the Creative Commons Attribution Non-Commercial License (http:// creativecommons.org/licenses/by-nc/3.0/), which permits unrestricted non-commercial use, distribution, and reproduction in any medium, provided the original work is properly cited. 
liver disease, accelerated arthritis, and other disabling or deadly conditions. The pathophysiology of type $2 \mathrm{DM}$ is characterized by peripheral insulin resistance, impaired regulation of hepatic glucose production and decreased beta cell function, eventually leading to beta cell failure. The primary goal of management in DM is to delay the macro- and microvascular complications by achieving good glycemic control and the relationship between tight glycemic control and microvascular disease in type $2 \mathrm{DM}$ is established [4].

Based on the encountering more DM surgical patients needing anesthesia, anesthesiologists will be more involved in the perioperative care, as the number of these patients. The enhanced understanding of rapidly evolving medical treatment for DM is helpful for anesthesiologist to manage the diabetic patients in the perioperative period with a rational basis. This article will review the current literature and incorporate new concepts, agents for the care of the patients with DM.

\section{Classification of Diabetes Mellitus}

Type 1 diabetes is called insulin dependent diabetes mellitus (IDDM) which is caused by pancreatic beta cell destruction, which results from an autoimmune attack by the body itself, and is rendered incapable of making insulin. Type 2 diabetes results from a combination of insulin resistance and a relative deficiency of insulin that is usually associated with defective insulin secretion [5] (Table 1).

\section{Diagnosis of Diabetes Mellitus}

In 1997, an International Expert Committee on the Diagnosis and Classification of Diabetes Mellitus published a new classification scheme and revised diagnostic criteria for DM, from the 1979 National Diabetes data Group and 1985 WHO study group (the following criteria are from the 2012 revision) [6]. The Expert Committee recognized an intermediate group

Table 1. Classification of Diabetes Mellitus

1. Type 1: Beta-cell destruction usually leading to absolute insulin
deficiency
2. Type 2: Insulin resistance with insulin secretion deficiency. 90-
$\quad 95 \%$ of people who have diabetes have Type 2.
3. Other specific types:
Genetic defects in beta-cell function
Genetic defects in insulin action
Exocrine pancreas diseases
Endocrinopathies
Drug or chemical induced
Infections
Other rare forms
4. Gestational: Insulin resistance with beta-cell dysfunction

of individuals whose glucose levels do not meet the criteria for diabetes, however, still higher than those considered normal. Several criteria may be used, independently, to establish the diagnosis. Any finding falling within the positive criteria should be repeated on a subsequent day with another test in any criteria set: e.g., random plasma glucose with symptoms, might be followed-up with a fasting plasma glucose level.

1) Fasting plasma glucose (FPG) $\geq 126 \mathrm{mg} / \mathrm{dl}(7.0 \mathrm{mmol} / \mathrm{L})$ on more than one occasion

2) Symptoms (such as polyuria, polydipsia, unexplained weight loss)

AND a random plasma glucose $\geq 200 \mathrm{mg} / \mathrm{dl}$ (11.1 mmol/L)

3) A 75 g oral glucose tolerance test with a 2 hour value of plasma glucose $\geq 200 \mathrm{mg} / \mathrm{dl}(11.1 \mathrm{mmol} / \mathrm{L})$

4) Hemoglobin $A_{1 C} \geq 6.5 \%$.

The 1997 guidelines included recommending the use of fasting plasma glucose as part of the diagnostic tests, but the cut-off point was reduced from 140 to $126 \mathrm{mg} / \mathrm{dl}$. Fasting plasma glucose values are preferred for their convenience, reproducibility, and correlation with increased risk of microvascular complication [7]. Since 1997, many studies relating to the diagnosis of DM have been reported and a number of questions have been raised about the use of fasting plasma glucose vs. oral glucose tolerance test. It has been known that impaired glucose tolerance is related with cardiovascular risk factors and events, whereas, impaired fasting glucose is less strongly related with cardiovascular events or mortality $[8,9]$. $\mathrm{HbA}_{1 \mathrm{c}}$ has many advantages including an indication of glucose concentrations over a number of weeks and useful monitor of both diagnosis and response to treatment. Recently, the use of $\mathrm{HbA}_{1 c}$, both as a diagnostic tool and as a predictor of perioperative outcomes has been studied and reported that $\mathrm{HbA}_{\mathrm{lc}}$ may have an important role in predicting perioperative outcomes in patients with DM undergoing a variety of surgical procedures $[10,11]$.

\section{Currently Used Drug Therapy}

Diet and exercise are first line treatments along with hypoglycemic drugs to achieve the goal of improving glycemic control, as well as preventing both microvascular and macrovascular complications. There are currently used distinct classes of hypoglycemic agents: biguanides, sulfonylureas, meglitinides, thiazolidinediones, a-glucosidase inhibitors, incretin mimetics, DPP-4 (Dipeptidyl Peptidase-IV) inhibitors and insulin (Tables 2 and 3$)$.

\section{Biguanides}

Biguinides are old agents that work by reducing hepatic glucose output and to a lesser extent, enhancing insulin sensi- 
Table 2. Oral Hypoglycemic Agents

\begin{tabular}{|c|c|c|c|c|}
\hline Class & Mechanism & Agents & Advantages & Disadvantages \\
\hline Biguinides & $\begin{array}{l}\text { Decrease hepatic } \\
\text { gluconeogenesis }\end{array}$ & Metformin & $\begin{array}{l}\text { No hypoglycemia, } \\
\text { weight neutral }\end{array}$ & $\begin{array}{l}\text { GI disturbance, } \\
\text { lactic acidosis }\end{array}$ \\
\hline Sulphonylureas & $\begin{array}{l}\text { Stimulate insulin } \\
\text { secretion }\end{array}$ & $\begin{array}{l}\text { Glimepiride, gliclazide, } \\
\text { glibenclamide, etc }\end{array}$ & Inexpensive & $\begin{array}{l}\text { Hypoglycemia, weight } \\
\text { gain }\end{array}$ \\
\hline Meglitinides & $\begin{array}{l}\text { Stimulate insulin } \\
\text { secretion }\end{array}$ & Repaglinide nateglinide & $\begin{array}{l}\text { Short onset of action, low } \\
\text { postprandial glucose }\end{array}$ & Hypoglycemia \\
\hline$\alpha$-Glucosidase inhibitors & $\begin{array}{l}\text { Decrease glucose } \\
\text { absorption }\end{array}$ & Acarbose, voglibose & $\begin{array}{l}\text { Reduce postprandial } \\
\text { glucose }\end{array}$ & GI flatulence \\
\hline Thiazolidinediones & $\begin{array}{l}\text { Improve insulin } \\
\text { resistance }\end{array}$ & Pioglitazone & $\begin{array}{l}\text { Lower insulin } \\
\text { requirements }\end{array}$ & $\begin{array}{l}\text { Edema, CHF, weight gain, } \\
\text { fracture, macula edema }\end{array}$ \\
\hline DPP 4 inhibitors & Prolong GLP-1 action & $\begin{array}{l}\text { Sitagliptine, vildagliptine, } \\
\text { saxagliptine, linagliptine }\end{array}$ & No hypoglycemia & Less clinical experience \\
\hline
\end{tabular}

Table 3. Parenteral Hypoglycemic Agents

\begin{tabular}{|c|c|c|c|c|}
\hline & Mechanism & Agents & Advantages & Disadvantages \\
\hline Insulin & Increase glucose utilization & $\begin{array}{l}\text { Human insulins, } \\
\text { Insulin analogues }\end{array}$ & Known safety profile & $\begin{array}{l}\text { Injection, hypoglycemia, } \\
\text { weight gain }\end{array}$ \\
\hline GLP-1 receptor agonists & $\begin{array}{l}\text { Stimulate insulin, } \\
\text { suppress glucagon, } \\
\text { slow gastric emptying }\end{array}$ & $\begin{array}{l}\text { Ezenatide } \\
\text { Liraglutide }\end{array}$ & $\begin{array}{l}\text { Reduce weight, no } \\
\text { hypoglycemia }\end{array}$ & $\begin{array}{l}\text { Injection, nausea, } \\
\text { pancreatitis, renal failure }\end{array}$ \\
\hline Amylin agonists & $\begin{array}{l}\text { Slow gastric emptying, } \\
\text { decrease glucagon }\end{array}$ & Pramintide & $\begin{array}{l}\text { Reduce postprandial } \\
\text { glucose, weight loss }\end{array}$ & Injection, nausea \\
\hline
\end{tabular}

tivity in hepatic and peripheral tissues [12]. Metformin still remains as the most widely used first-line for type $2 \mathrm{DM}$. Metformin should be prescribed to all people with type $2 \mathrm{DM}$, unless contraindicated. Current recommendations of the American Diabetes Association and European Association for the Study of Diabetes include metformin, diet and exercise as first-line therapy for the treatment of patients with type 2 $\mathrm{DM}$, irrespective of the presence of overweight status [13]. It is generally considered weight-neutral with chronic use and does not increase the risk of hypoglycemia when used as monotherapy [14]. But, hypoglycemia can occur when used in combination with sulphonylureas or insulin. Metformin is related with initial gastrointestinal side effects, and caution is advised to avoid its use in patients at risk for lactic acidosis. Less than $60 \mathrm{ml} / \mathrm{min}$ of a glomerular filtration rate value would be the approximate equivalent of the above serum creatinine cutoffs ( $1.4 \mathrm{mg} / \mathrm{dl}$ in women and $1.5 \mathrm{mg} / \mathrm{dl}$ in men), and metformin should be discontinued [14]. It is very relevant to remember that patients who are about to receive intravenous iodinated contrast material with potential for contrast induced renal failure or undergo a surgical procedure with potential compromise of the circulation should have metformin stopped, until stable renal function can be established (normal urine output, normal serum creatinine and no evidence of fluid overload or circulatory compromise).

\section{Sulfonylureas}

Sulfonylureas were the mainstay of antidiabetic therapy since the early 1950s. The oldest oral agent class is the sulfonylurea insulin secretagogues. They work by stimulating insulin release from the insulin secreting $\beta$ cells, which are located in the pancreas [15], and may slightly improve insulin resistance in peripheral target tissues (muscle, fat). First-generation sulfonylureas, such as chlorpropamide, tolazamide and tolbutamide, have a longer half-life, a greater incidence of hypoglycemia, more frequent drug interactions, and are now rarely used. A newer sulfonylurea, glimepiride, has a more rapid onset of action and a better coverage of the postprandial glucose rise and less risk of hypoglycemia [16]. They cause greater suppression of overnight hepatic glucose output, thereby, further lowering fasting blood glucose concentrations. These agents, especially the longer acting ones, have the potential to cause hypoglycemia, especially in elderly individuals. Hypoglycemia is usually related to delayed meals, increased physical activity, alcohol intake, or renal insufficiency. All sulfonylurea have been associated with weight gain, unless the diabetic diet and exercise program are followed [16]. The choice of sulfonylurea is primarily dependent upon the cost and availability, because their efficacy against microvascular and cardiovascular complications is similar [17]. 


\section{Meglitinides}

The meglitinides (Repaglinide and nateglinide) are structurally different than sulfonylureas, but their mechanism of action closely resembles that of sulfonylureas because they stimulate the release of insulin from the pancreatic beta cells through a different binding site on the sulfonylurea receptor. The meglitinides can be used as monotherapy, or in combination with other oral hypoglycemic drugs, like metformin, which results in superior glycemic control than with either agent used as monotherapy. Their clinical efficacy is similar to that of the sulfonylureas. Some potential advantages of this class of agents include a greater decrease in postprandial glucose and a decreased risk of hypoglycemia [18].

\section{Thiazolidinediones}

Thiazolidinediones (TZDs) improve insulin sensitivity in the skeletal muscle by increasing the efficacy of glucose transporters, lowering $\mathrm{HbA}_{1 \mathrm{c}}$ and reducing both fasting and postprandial glucose concentrations [19]. They do not increase the risk of hypoglycemia when used as a single agents, and may be more durable in their effectiveness than sulfonylureas and metformin [20]. Pioglitazone appeared to have a modest benefit on cardiovascular events as a secondary outcome in one large trial involving patients with overt macrovascular disease [21]. Thiazolidinediones are associated with weight gain $(2-3 \mathrm{~kg})$, a small reduction in the hematocrit, and a mild increase in plasma volume. Peripheral edema and congestive heart failure are more common in individuals treated with these agents with the incidence ranging from $2.5 \%$ to $16.2 \%$. This risk is increased with age, drug dose, female, impaired renal function, and concomitant insulin use. These agents are contraindicated in patients with liver disease or congestive heart failure (New York Heart Association class III or IV) [22].

\section{a-Glucosidase inhibitors}

$\alpha$-Glucosidase inhibitors include acarbose and voglibose. They block the enzyme $\alpha$-glucosidase, found in brush border cells of small intestine, cleaving more complex carbohydrates into sugars. These agents delay absorption of glucose and decrease meal-related blood glucose increases. Thereby, these agents are most useful in patients who have mild fasting plasma glucose elevations or in patients with predominant postprandial hyperglycemia [23]. The major side effects such as diarrhea, flatulence, and abdominal distension, are related to increased delivery of oligosaccharides to the large bowel, and can be reduced somewhat by gradual upward dose titration. These agents should not be used in individuals with inflammatory bowel disease, gastroparesis, or a serum creatinine $>2.0 \mathrm{mg} /$ dl) [24].

\section{Incretins/ GLP-1(Glucagon-Like Peptide-1) agonists}

Incretins (glucagon like peptide-1 and glucose dependent insulinotropic polypeptide) are enteroendocrine hormones released into the bloodstream from L cells of ileum and colon and $\mathrm{K}$ cells of duodenum and jejunum [25]. The effect of incretins refers to the augmented release of insulin from oral ingestion of glucose. The injectable GLP-1 receptor agonists mimic the effects of endogenous GLP-1, thereby, stimulating pancreatic insulin secretion in a glucose-dependent fashion, suppressing pancreatic glucagon output, slowing gastric emptying, and decreasing appetite (Table 3). Exenatide is an analogue of GLP-1. Exenatide has prolonged GLP-1-like action, and binds to GLP-1 receptors found in islets, the gastrointestinal tract, and the brain [26]. Liraglutide, another GLP-1 receptor agonist, is almost identical to native GLP-1 with a long half-life. GLP-1 receptor agonists increase glucose-stimulated insulin secretion, suppress glucagon, and slow gastric emptying [27]. Their main advantage is weight loss, which is modest in most patients but can be significant in some. A limiting side effect is nausea and less commonly, vomiting or diarrhea, particularly early in the course of the treatment. Incretin therapy appears to provide an effective alternative to the currently available hypoglycemic agents [28].

\section{DPP-4 inhibitors}

DPP-IV inhibitors inhibit degradation of native GLP-1 and thus, enhance the incretin effect. DPP-IV, which is widely expressed on the cell surface of endothelial cells and some lymphocytes, degrades a wide range of peptides (not GLP-1 specific). These enhance circulating concentrations of active GLP-1 [29]. DPP-4 inhibitors mimic the therapeutic effects of incretin mimetics including stimulation of insulin secretion, inhibition of glucagon secretion, possibly preservation of $\beta$-cell mass and inhibition of apoptosis. These drugs display similar efficacy in lowering $\mathrm{HbA}_{1 \mathrm{c}}$ compared with other antihyperglycemic agents. They do not reduce the appetite or cause weight loss, such as GLP-1 agonists, and have a low potential for hypoglycaemia when used as monotherapy [30]. One safety concern involves the potential of DPP-4 inhibitors to interfere with the immune functions: a meta-analysis of pooled clinical trial data for sitagliptin and vildagliptin indicates an increased risk for infection (nasopharyngitis and urinary tract infection) and headache [31]. 


\section{Insulin}

Due to the progressive $\beta$-cell dysfunction that characterizes type 2 diabetes, insulin replacement therapy is frequently required [32]. Importantly, most patients maintain some endogenous insulin secretions, even in late stages of the disease. Starting insulin therapy with low doses in combination with oral agents is effective in the control of glycemic level and maintaining $\mathrm{HbA}_{1 \mathrm{C}}$ values [33].

Insulins can be classified as short-acting or long-acting (Table 4). Short acting insulin analogues are lispro, aspart and glulisine. Insulin lispro is an insulin analogue, in which the 28th and 29th amino acids (lysine and proline) on the insulin B-chain have been reversed by recombinant DNA technology. Insulin aspart and insulin glulisine are other genetically modified insulin analogues with properties similar to lispro. These insulin analogues have full biologic activity, but fewer tendencies for self-aggregation, results in more rapid absorption and onset of action and a shorter duration of action [34]. Long acting insulin analogues are glargine and detemir. Insulin glargine is longacting biosynthetic human insulin, which differs from that of normal insulin. Compared to the neutral protamine Hegedorn $(\mathrm{NPH})$ insulin, it is released very slowly from the injection site and its duration of action is prolonged, allowing a relatively constant basal insulin supply without peak for more than 24 hours. A lower incidence of hypoglycemia, especially at night, has been reported with insulin glargine when compared to NPH insulin [33].

The principle of insulin use is the creation of as normal a glycemic profile as possible without unacceptable weight gain or hypoglycemia. As initial therapy, unless the patient is markedly hyperglycemic and/or symptomatic, basal insulin is typically added [35]. Basal insulin provides relatively uniform insulin coverage throughout day and night, which mainly controls blood glucose by suppressing hepatic glucose production in between meals and during sleep. Either intermediate-acting (NPH) or long-acting (glargine or detemir) formulations may be used. Although the majority of patients with type 2 diabetes requiring insulin therapy can be successfully treated with basal insulin alone, because of progressive diminution in their insulin secretory capacity, some will require prandial insulin therapy with shorter-acting insulins. Newer fast acting analogues, such as insulin lispro, insulin aspart, or insulin glargine, have a rapid onset of action and 4-5 hours of action duration that is normal meal time peaks of plasma insulin more closely than human regular insulin, therefore, immediate post-prandial hyperglycemia and late post-prandial hypoglycemia is rare [33].

There have been recent reports suggesting increased risk of cancer (colon, pancreas, breast and liver cancer) in patients taking long acting insulins. Cancers linked with DM are also associated with obesity or insulin resistance, so the cause may be multifactorial [36].

\section{Anesthetic Consideration}

According to the increasing diabetic population worldwide, anesthesiologists have a more chances to encounter patients with DM in the management of perioperative period. Nondiabetic patients may become hyperglycemic state due to a combination of tissue insulin resistance and decreased insulin secretion in the perioperative period. In diabetic patients, surgery and trauma are associated with an increase in the secretion of

Table 4. Action Duration of Insulins

\begin{tabular}{|c|c|c|c|}
\hline Insulins & Onset time & Peak time & Action duration \\
\hline \multicolumn{4}{|l|}{ Short acting insulin } \\
\hline \multicolumn{4}{|l|}{ Human } \\
\hline Regular & $30-60 \mathrm{~min}$ & $2-3 \mathrm{hr}$ & $4-6 \mathrm{hr}$ \\
\hline \multicolumn{4}{|l|}{ Analogues } \\
\hline Aspart & $5-15 \mathrm{~min}$ & $30-90 \mathrm{~min}$ & $3-4 \mathrm{hr}$ \\
\hline Gluisine & $5-15 \min$ & $30-90 \mathrm{~min}$ & $3-4 \mathrm{hr}$ \\
\hline Lispro & $5-15 \min$ & $30-90 \mathrm{~min}$ & $3-4 \mathrm{hr}$ \\
\hline \multicolumn{4}{|l|}{ Long acting insulin } \\
\hline \multicolumn{4}{|l|}{ Human insulin } \\
\hline $\mathrm{NPH}$ & $1-4 \mathrm{hr}$ & $6-10 \mathrm{hr}$ & $10-16 \mathrm{hr}$ \\
\hline \multicolumn{4}{|l|}{ Analogues } \\
\hline Detemir & $1-4 \mathrm{hr}$ & Minimal & $\sim 24 \mathrm{hr}$ \\
\hline Glargine & $1-4 \mathrm{hr}$ & Minimal & $\sim 24 \mathrm{hr}$ \\
\hline \multicolumn{4}{|l|}{ Premixed insulin } \\
\hline $75 / 25-75 \%$ protamine lispro, $25 \%$ lispro & $5-15 \min$ & $90 \mathrm{~min}$ & $10-16 \mathrm{hr}$ \\
\hline $70 / 30-70 \%$ protamine aspart, $30 \%$ aspart & $5-15 \min$ & $90 \mathrm{~min}$ & $10-16 \mathrm{hr}$ \\
\hline $50 / 50-50 \%$ protamine lispro, $50 \%$ lispro & $5-15 \min$ & $90 \mathrm{~min}$ & $10-16 \mathrm{hr}$ \\
\hline $70 / 30-70 \% \mathrm{NPH}, 30 \%$ regular & $30-60 \mathrm{~min}$ & Dual & $10-16 \mathrm{hr}$ \\
\hline
\end{tabular}


catabolic hormones in the presence of relative insulin deficiency. Therefore, the aim of perioperative metabolic management should be to avoid excessive hyperglycemia, hypoglycemia and loss of electrolyte such as potassium, magnesium and phosphate [37].

It is known that long-term intensive glycemic control in type 2 diabetic patient significantly reduced microvascular (retinopathy, nephropathy, neuropathy) complications [4,7]. In addition, control of hypertension and dyslipidemia is essential, blood pressure $<130 / 85 \mathrm{mmHg}$ and a low density lipoprotein cholesterol level $<100 \mathrm{mg} / \mathrm{dl}$ are suggested a standard of care [38]. Observational study of 3,112 cases by Frisch et al. [39] showed that perioperative hyperglycemia is associated with increased hospital length of stay, hospital complications, and mortality after noncardiac general surgery. Especially, in this study, the rate of postoperative complications such as pneumonia, wound infection, urinary tract infection, acute myocardial infarction, and acute renal failure, was higher in diabetic patients than nondiabetics during the hospital stay. Tight glucose control in perioperative period has been recommended from a seminal study of 1,548 intensive care patients by Van den Berghe et al. [40], mostly post-cardiac surgery. In this study, tight glycemic control (blood glucose maintained in the range $80-110 \mathrm{mg} / \mathrm{dl}$ ) showed decreased mortality rate than normal glycemic control (blood glucose maintained below $216 \mathrm{mg}$ / $\mathrm{dl}$ ), from $8.0 \%$ to $4.6 \%$ in patients who remained in intensive unit for over 5 days. Also, intensive insulin therapy in this study was associated with a decrease in the incidence of bloodstream infections, acute renal failure, polyneuropathy, and a decrease in the incidence of mortality from multi-organ failure. But, in this Belgian study, approximately $5 \%$ of the patients had hypoglycemic episodes despite the increased scrutiny of an intensive care. The other large observational study of Finney et al. [41] argued for maximal benefit in the range of 144 to $180 \mathrm{mg} /$ dl. Therefore, even if these studies are postulated that insulin therapy is not harmful, and may even be beneficial, it is unclear what targets of glycemic control are appropriate. It is clear that tighter control necessitates more insulin included its potential harmful effects, and the risk for hypoglycemia increase.

Inadvertent hypoglycemia should be seriously considered in diabetic patients during the perioperative period, because hypoglycemia under anesthesia may be longer in duration and more severe than in patients who might manifest symptoms, such as tachycardia, sweating, pallor, light-headedness, restlessness, confusion, even unconsciousness, and frequent blood glucose estimations are essential [42]. New drugs, such as incretin and amylin analogues, may show hypoglycemia as an adverse effect, particularly, if used in conjunction with an insulin preparation or sulfonylurea $[28,43]$. Decreasing the dose of pre-meal insulin or sulfonylurea may need to avoid hypoglycemia. These adverse effects may occur particularly in the first 4 weeks of treatment, and declines over time. These new agents have only recently appeared in clinical practice, consequently, adverse effects in anesthetized or surgical patients may not been reported. New long acting insulin, such as glargine and detemir, shows good glycemic control between meals without the risk of hypoglycemia, so they can be used as a basal insulin during the perioperative period without stopping before the day of surgery [44].

Nausea is the most common adverse effect associated with incretins and amylin pathways. Nausea is generally mild to moderate, and vomiting is less frequent, most prevalent in the early state of the treatment, in the 4-8 weeks, after than generally declines. However, vomiting still occurs in approximately $17 \%$ of the patients treated with exenatide [28]. Although there are no published reports of postoperative nausea and vomiting attributed to incretin and amylin pathways, it seems reasonable to expect that patients treated with these agents may experience more severe, or frequent postoperative nausea and vomiting. Therefore, it seems logical to withhold these agents in the perioperative period to reduce the likelihood or intensity of postoperative nausea and vomiting. Future clinical studies may provide evidence based recommendations of these agents for the surgery and anesthesia.

Delaying gastric empting by incretin peptides and amylin pathways is one of the mechanisms of these agents that decrease postprandial glucose levels. Gastroparesis is a feature of advanced DM and these agents that slow gastric empting may exacerbate this problem [45]. Incretin and amylin pathways seem reasonable to expect an increased risk of aspiration with these agents during the perioperative period, especially, those patients with peripheral neuropathy and gastroparesis as manifestation of DM.

\section{Conclusion}

As the newer treatments for DM become increasingly prevalent in clinical practice, clinical experience accumulates with these agents in anesthetized patients, and more definitive recommendations may be provided. Anesthesiologists should have a concerns based on the physiology and pharmacology of the currently used novel therapies for the treatment of DM. Also, the adverse effects and interactions of new agents that need more clinical experiences should be considered for the diabetic patients during the perioperative management.

\section{References}

1. The global challenge of diabetes. Lancet 2008; 371: 1723.

2. Task Force Team for Basic Statistical Study of Korean Diabetes 
Mellitus. Report of Task Force Team for Basic Statistical Study of Korean Diabetes Mellitus: diabetes in Korea 2007. Seoul, Goldfishery. 2007, pp 14-21.

3. Kim DJ. The Epidemiology of diabetes in Korea. Diabetes Metab J 2011; 35: 303-8.

4. Intensive blood-glucose control with sulphonylureas or insulin compared with conventional treatment and risk of complications in patients with type 2 diabetes (UKPDS 33). UK Prospective Diabetes Study (UKPDS) Group. Lancet 1998; 352: 837-53.

5. American Diabetes Association. Diagnosis and classification of diabetes mellitus. Diabetes Care 2004; 27 Suppl 1: S5-S10.

6. Report of the expert committee on the diagnosis and classification of diabetes mellitus. Diabetes Care 1997; 20: 1183-97.

7. Tight blood pressure control and risk of macrovascular and microvascular complications in type 2 diabetes: UKPDS 38. UK Prospective Diabetes Study Group. BMJ 1998; 317: 703-13.

8. Hanefeld M, Temelkova-Kurktschiev T, Schaper F, Henkel E, Siegert $\mathrm{G}$, Koehler C. Impaired fasting glucose is not a risk factor for atherosclerosis. Diabet Med 1999; 16: 212-8.

9. DECODE Study Group, European Diabetes Epidemiology Group. Is the current definition for diabetes relevant to mortality risk from all causes and cardiovascular and noncardiovascular diseases? Diabetes Care 2003; 26: 688-96.

10. Halkos ME, Lattouf OM, Puskas JD, Kilgo P, Cooper WA, Morris CD, et al. Elevated preoperative hemoglobin Alc level is associated with reduced long-term survival after coronary artery bypass surgery. Ann Thorac Surg 2008; 86: 1431-7.

11. Marchant MH Jr, Viens NA, Cook C, Vail TP, Bolognesi MP. The impact of glycemic control and diabetes mellitus on perioperative outcomes after total joint arthroplasty. J Bone Joint Surg Am 2009; 91: 1621-9.

12. Bailey CJ, Turner RC. Metformin. N Engl J Med 1996; 334: 574-9.

13. Inzucchi SE, Bergenstal RM, Buse JB, Diamant M, Ferrannini E, Nauck M, et al. Management of hyperglycaemia in type 2 diabetes: a patient-centered approach. Position statement of the American Diabetes Association (ADA) and the European Association for the Study of Diabetes (EASD). Diabetologia 2012; 55: 1577-96.

14. Mahler RJ. Metformin: actions and indications for use in noninsulin-dependent diabetes mellitus. Endocr Pract 1995; 1: 418-22.

15. Aguilar-Bryan L, Nichols CG, Wechsler SW, Clement JP 4th, Boyd AE 3rd, Gonzalez G, et al. Cloning of the beta cell high-affinity sulfonylurea receptor: a regulator of insulin secretion. Science 1995; 268: 423-6.

16. Leibowitz G, Cerasi E. Sulphonylurea treatment of NIDDM patients with cardiovascular disease: a mixed blessing? Diabetologia 1996; 39: 503-14.

17. Zoungas S, de Galan BE, Ninomiya T, Grobbee D, Hamet P, Heller $\mathrm{S}$, et al. Combined effects of routine blood pressure lowering and intensive glucose control on macrovascular and microvascular outcomes in patients with type 2 diabetes: New results from the ADVANCE trial. Diabetes Care 2009; 32: 2068-74.

18. Fuhlendorff J, Rorsman P, Kofod H, Brand CL, Rolin B, MacKay P, et al. Stimulation of insulin release by repaglinide and glibenclamide involves both common and distinct processes. Diabetes 1998; 47: 345-51.

19. Yki-Jarvinen H. Thiazolidinediones. N Engl J Med 2004; 351: 1106-
18.

20. Kahn SE, Haffner SM, Heise MA, Herman WH, Holman RR, Jones NP, et al. Glycemic durability of rosiglitazone, metformin, or glyburide monotherapy. N Engl J Med 2006; 355: 2427-43.

21. Dormandy JA, Charbonnel B, Eckland DJ, Erdmann E, MassiBenedetti M, Moules IK, et al. Secondary prevention of macrovascular events in patients with type 2 diabetes in the PROactive Study (PROspective pioglitAzone Clinical Trial In macroVascular Events): a randomised controlled trial. Lancet 2005; 366: 1279-89.

22. Nesto RW, Bell D, Bonow RO, Fonseca V, Grundy SM, Horton ES, et al. Thiazolidinedione use, fluid retention, and congestive heart failure: a consensus statement from the American Heart Association and American Diabetes Association. October 7, 2003. Circulation 2003; 108: 2941-8.

23. Chiasson JL, Josse RG, Hunt JA, Palmason C, Rodger NW, Ross SA, et al. The efficacy of acarbose in the treatment of patients with noninsulin-dependent diabetes mellitus. A multicenter controlled clinical trial. Ann Intern Med 1994; 121: 928-35.

24. Sheehan MT. Current therapeutic options in type 2 diabetes mellitus: a practical approach. Clin Med Res 2003; 1: 189-200.

25. Kennedy L. Incretin-based therapies for type 2 diabetes mellitus: New therapeutic mechanisms. Cleve Clin J Med 2009; 76 Suppl 5: S2-3.

26. Drucker DJ. The biology of incretin hormones. Cell Metab 2006; 3: 153-65.

27. Juhl CB, Hollingdal M, Sturis J, Jakobsen G, Agerso H, Veldhuis J, et al. Bedtime administration of NN2211, a long-acting GLP-1 derivative, substantially reduces fasting and postprandial glycemia in type 2 diabetes. Diabetes 2002; 51: 424-9.

28. Amori RE, Lau J, Pittas AG. Efficacy and safety of incretin therapy in type 2 diabetes: systematic review and meta-analysis. JAMA 2007; 298: 194-206.

29. Deacon CF. Dipeptidyl peptidase-4 inhibitors in the treatment of type 2 diabetes: a comparative review. Diabetes Obes Metab 2011; 13: 7-18.

30. Pratley RE, Salsali A. Inhibition of DPP-4: a new therapeutic approach for the treatment of type 2 diabetes. Curr Med Res Opin 2007; 23: 919-31.

31. Wright DH, Herman GA, Maes A, Liu Q, Johnson-Levonas AO, Wagner JA. Multiple doses of sitagliptin, a selective DPP-4 inhibitor, do not meaningfully alter pharmacokinetics and pharmacodynamics of warfarin. J Clin Pharmacol 2009; 49: 1157-67.

32. Jabbour S. Primary care physicians and insulin initiation: multiple barriers, lack of knowledge or both? Int J Clin Pract 2008; 62: 845-7.

33. Wyne KL, Mora PF. Insulin therapy in type 2 diabetes. Endocr Res 2007; 32: 71-107.

34. Holleman F, Hoekstra JB. Insulin lispro. N Engl J Med 1997; 337: 176-83.

35. Holman RR, Farmer AJ, Davies MJ, Levy JC, Darbyshire JL, Keenan JF, et al. Three-year efficacy of complex insulin regimens in type 2 diabetes. N Engl J Med 2009; 361: 1736-47.

36. Smith U, Gale EA. Does diabetes therapy influence the risk of cancer? Diabetologia 2009; 52: 1699-708.

37. Robertshaw HJ, Hall GM. Diabetes mellitus: anaesthetic management. Anaesthesia 2006; 61: 1187-90.

38. The sixth report of the Joint National Committee on prevention, 
detection, evaluation, and treatment of high blood pressure. Arch Intern Med 1997; 157: 2413-46.

39. Frisch A, Chandra P, Smiley D, Peng L, Rizzo M, Gatcliffe C, et al. Prevalence and clinical outcome of hyperglycemia in the perioperative period in noncardiac surgery. Diabetes Care 2010; 33: 1783-8.

40. van den Berghe G, Wouters P, Weekers F, Verwaest C, Bruyninckx F, Schetz M, et al. Intensive insulin therapy in critically ill patients. N Engl J Med 2001; 345: 1359-67.

41. Finney SJ, Zekveld C, Elia A, Evans TW. Glucose control and mortality in critically ill patients. JAMA 2003; 290: 2041-7.
42. Hirsch IB, McGill JB, Cryer PE, White PF. Perioperative management of surgical patients with diabetes mellitus. Anesthesiology 1991; 74: 346-59.

43. Ryan GJ, Jobe LJ, Martin R. Pramlintide in the treatment of type 1 and type 2 diabetes mellitus. Clin Ther 2005; 27: 1500-12.

44. Kang H, Ahn KJ, Choi JY, Park HJ, Park SJ, Lee SK. Efficacy of insulin glargine in perioperative glucose control in type 2 diabetic patients. Eur J Anaesthesiol 2009; 26: 666-70.

45. Cure P, Pileggi A, Alejandro R. Exenatide and rare adverse events. N Engl J Med 2008; 358: 1969-70. 